\title{
A comparative study of intracervical foley's catheter with oxytocin and vaginal misoprostol for induction of labour
}

\author{
Priyanka*, Shashi Bala Arya, Mridu Sinha, J. K. Goel
}

\begin{abstract}
Department of Obstetrics and Gynecology, Shri Ram Murti Smarak Institute of Medical Sciences, Bareilly, Uttar
\end{abstract} Pradesh, India

Received: 24 April 2019

Revised: 25 July 2020

Accepted: 31 July 2020

\author{
*Correspondence: \\ Dr. Priyanka, \\ E-mail: priya.adi2008@gmail.com
}

Copyright: () the author(s), publisher and licensee Medip Academy. This is an open-access article distributed under the terms of the Creative Commons Attribution Non-Commercial License, which permits unrestricted non-commercial use, distribution, and reproduction in any medium, provided the original work is properly cited.

\begin{abstract}
Background: Induction of labour implies stimulation of uterine contraction before spontaneous onset of labour with or without ruptured membranes. Aim of this study was to compare the efficacy and safety of intracervical Foley's catheter with oxytocin and vaginal misoprostol for labour induction at term.

Methods: A total 100 term pregnant women were chosen with bishop score <6 and divided into two groups: Foley's catheter with oxytocin (Group A) and vaginal misoprostol (Group B). In Group A, a 16 F Foley's catheter introduced beyond internal os and traction applied every 4 hourly to check for expulsion with simultaneous oxytocin infusion (2 $\mathrm{mU} / \mathrm{min}$ up to $32 \mathrm{mU} / \mathrm{min}$ ). In Group B, $25 \mathrm{mcg}$ misoprostol administered every 4 hourly (maximum 6 doses or 150 $\mathrm{mcg}$ ). Data analysed using SPSS software 20.0. A p value $<0.05$ was considered statistically significant.

Results: No statistical difference found between demographic variables between two groups. Both primigravida and multigravida had poor pre-induction bishop score in both groups. Foley's catheter (80\%) and misoprostol group $(96 \%)$ had successful induction and was statistically significant $(\mathrm{p}<0.05)$. Foley's catheter took more time from induction-delivery both in primigravida and post-dated pregnant women. The rate of cesarean in Foley's catheter group was high $(62.5 \%)$ including $33 \%$ cases with failed induction. Foley's catheter had less maternal and neonatal complications, less NICU admission as compared to misoprostol ( $\mathrm{p}>0.05)$.

Conclusions: Misoprostol was found better for successful induction, decreases induction-to-delivery interval and increases vaginal delivery as compared to Foley's catheter but it needs constant supervision in view of hyperstimulation and tachysystole.
\end{abstract}

Keywords: Foley’s catheter, Labour induction, Vaginal misoprostol

\section{INTRODUCTION}

Induction of labour implies stimulation of uterine contraction before spontaneous onset of labour with or without ruptured membranes. ${ }^{1}$ About $20 \%$ of all pregnancies require induction of labour. It helps in the achievement of the vaginal delivery in the shortest possible time without compromising the maternal and fetal safety. ${ }^{2,3}$ Common medical and obstetrical indications requiring inductions include premature rupture of membranes, gestational hypertension, post- dated pregnancy, oligohydramnios, intrauterine growth restriction, chronic hypertension and diabetes; most common being post-dated pregnancy. ${ }^{4,5}$

In order to be successful, induction of labour must fulfil following aims; first-it should result in labour that is adequate uterine contractions and progressive dilatation of cervix. Second-it should result in vaginal delivery. Achievement of these goals largely depends on the condition of the cervix, thus, a woman whose cervix is 2 $\mathrm{cm}$ dilated, $80 \%$ effaced, soft, and mid position with fetal 
occiput at -1 station would have a successful induction of labour. $^{6}$

The induction is defined as failed when a patient who was induced but has not entered the active phase of labour despite adequate management for $24-48$ hours. $^{7}$

\section{Ideal cervical ripening agent should}

1. Cause cervical changes in a physiological manner similar to natural ripening process

2. Not affect uterine blood flow and feto- maternal unit that would necessitate close monitoring

3. Free of maternal side effects

4. Not jeopardize future pregnancy

5. Safe, practical, acceptable to patient and economically feasible.

The most common methods of labour induction involve intravaginal use of misoprostol, transcervical insertion of Foley's catheter, intravenous oxytocin infusion and insertion of prostaglandin gels. ${ }^{8}$

The use of intra-cervical Foley's catheter is the main nonpharmacological method of cervical ripening and induction of labour. Misoprostol (PGE1) is at present receiving more attention as an effective cervical modifying agent and labour induction. It is cheap, easy to handle and also can be stored at room temperature. ${ }^{9}$

\section{METHODS}

This comparative prospective study was conducted among 100 term antenatal patients, from November 2016 to May 2018 in this study tertiary care institute, Shri Ram Murti Smarak Institute of Medical Sciences, Bareilly according to selection criteria.

\section{Study technique}

The study protocol included a predesigned and prestructured questionnaire. Thorough history taking was done followed by general and systemic examination of the patients.

\section{Inclusion criteria}

Primi or $2^{\text {nd }}$ gravida, term gestation (37-40 weeks), single live fetus with cephalic presentation, reassuring fetal status, bishop score of $\leq 6$ requiring induction, IUGR, gestational hypertension, mild pre-eclampsia, post-dated pregnancy, elderly gravida, borderline oligohydramnios $(5-8 \mathrm{~cm})$.

Bishop scoring and non-stress test was done prior to induction. 100 women assigned into 2 groups, 50 in each.

Group A: Induction was done with number 16 F Foley's catheter and balloon inflated with $30 \mathrm{ml}$ sterile water and traction applied every 4 hourly to check for balloon extrusion. Oxytocin infusion started with an initial dose of $2 \mathrm{mU} / \mathrm{min}$ and escalated every $30 \mathrm{~min}$ till women went into active labour (>4 cm cervical dilatation) or maximum dose of $32 \mathrm{mU} / \mathrm{min}$. If labour failed to start at end of 24 hours of maximum dose, oxytocin drip was discontinued and the method was considered as failed.

Group B: Patients induced with $25 \mathrm{mcg}$ misoprostol tablets per vaginally and repeated every $4^{\text {th }}$ hourly until she goes in active labour with maximum of 6 doses (150 $\mathrm{mcg}$ ). If labour did not ensue after 4 hours following last dose or women did not went into active labour in 24 hours, it was considered as failed induction.

\section{Statistical analysis}

Appropriate statistical methods proposed for the study was applied and evaluated using SPSS ver. 20.0.

\section{RESULTS}

Maximum number of pregnant women $80 \%$ in Group A and $78 \%$ women in Group B were primigravida. $20 \%$ in Group A and 22\% pregnant women in Group B were multigravida. Majority of the pregnant women $76 \%$ in each Group A and Group B fall in 37-40 weeks period of gestation (Table 1).

Table 1: Demographic profile.

\begin{tabular}{|llll|}
\hline Parameters & $\begin{array}{l}\text { Group A } \\
(\%)\end{array}$ & $\begin{array}{l}\text { Group B } \\
(\%)\end{array}$ & P value \\
\cline { 1 - 3 } Parity- primi & 80 & 78 & \multirow{2}{*}{0.806} \\
\hline Multi & 20 & 22 & \multirow{2}{*}{1.0} \\
\hline POG- <40 weeks & 76 & 76 & \\
\hline >40 weeks & 24 & 24 & \\
\hline
\end{tabular}

Table 2: Maternal dynamics.

\begin{tabular}{|c|c|c|c|}
\hline Parameters & $\begin{array}{l}\text { Group A } \\
(\%)\end{array}$ & $\begin{array}{l}\text { Group B } \\
(\%)\end{array}$ & $P$ value \\
\hline \multicolumn{3}{|l|}{ Bishop score } & \multirow{3}{*}{0.134} \\
\hline $0-3$ & 26 & 14 & \\
\hline $4-6$ & 74 & 86 & \\
\hline \multicolumn{3}{|l|}{ IOL indication } & \multirow{3}{*}{0.85} \\
\hline Oligohydramnios & 48 & 42 & \\
\hline Post dated & 28 & 30 & \\
\hline
\end{tabular}

Most of pregnant women had bishop score of 4-6 i.e. $74 \%$ in Group A and $86 \%$ women in Group B. Majority of pregnant women in Group A i.e.48\% were induced with indication of borderline oligohydramnios while those in Group B were $42 \%$ women. In Group A, $28 \%$ women had post-dated pregnancy in comparison to those in Group B which included 30\% women (Table 2).

Maximum pregnant women had successful induction in both Group A (80\%) and Group B (96\%). The difference was significant with $\mathrm{p}$ value of 0.013. Among 
successfully induced pregnant women in Group A, primigravida took $13.45 \pm 4.87$ hours as mean time from induction to onset of active phase of labour to that of $9.20 \pm 4.75$ hours in Group B. Whereas in multigravida women, Group A took 11.19 \pm 5.71 hours as mean time between induction to onset of active phase while group B took $8.52 \pm 3.54$ hours. Women with gestational age $>40$ weeks in Group A had mean time of $14.17 \pm 3.53$ hours whereas in Group B had mean time of 11.52 \pm 4.06 hours. Primigravida women in Group A had mean time of $20.11 \pm 6.34$ hours from induction to delivery interval whereas Group B took $14.33 \pm 5.28$ hours. Group A with gestational age $>40$ weeks had mean time of $20.56 \pm 4.56$ hours whereas Group B had mean time of $14.46 \pm 4.28$ hours from induction to delivery (Table 3 ).

Table 3: Outcome of induction and labour dynamics.

\begin{tabular}{|c|c|c|c|}
\hline Parameters & $\begin{array}{l}\text { Group A } \\
(\%)\end{array}$ & $\begin{array}{l}\text { Group B } \\
(\%)\end{array}$ & $\begin{array}{l}\mathbf{P} \\
\text { value }\end{array}$ \\
\hline \multicolumn{3}{|l|}{ Induction } & \multirow{3}{*}{0.013} \\
\hline Successful & 80 & 96 & \\
\hline Unsuccessful & 20 & 4 & \\
\hline \multicolumn{4}{|l|}{ I-A phase } \\
\hline Primi & $13.45 \pm 4.87$ & $9.20 \pm 4.75$ & 0.41 \\
\hline Multi & $11.19 \pm 5.71$ & $8.52 \pm 3.54$ & 0.39 \\
\hline$<40$ weeks & $12.42 \pm 4.87$ & $8.03 \pm 3.48$ & 0.42 \\
\hline$>40$ weeks & $14.17 \pm 3.53$ & $11.52 \pm 4.06$ & 0.48 \\
\hline \multicolumn{4}{|l|}{ I-D time } \\
\hline Primi & $20.11 \pm 6.34$ & $14.33 \pm 5.28$ & 0.38 \\
\hline Multi & $15.44 \pm 4.08$ & $13.54 \pm 4.73$ & 0.35 \\
\hline$<40$ weeks & $16.52 \pm 4.26$ & $10.36 \pm 3.38$ & 0.37 \\
\hline$>40$ weeks & $20.56 \pm 4.56$ & $14.46 \pm 4.28$ & 0.39 \\
\hline
\end{tabular}

Table 4: Delivery outcome.

\begin{tabular}{|c|c|c|c|}
\hline Parameters & $\begin{array}{l}\text { Group A } \\
(\%)\end{array}$ & $\begin{array}{l}\text { Group B } \\
(\%)\end{array}$ & $\begin{array}{l}P \\
\text { value }\end{array}$ \\
\hline \multicolumn{3}{|l|}{ Mode } & \multirow{3}{*}{0.01} \\
\hline Vaginal & 38.5 & 61.5 & \\
\hline LSCS & 62.5 & 37.5 & \\
\hline \multicolumn{3}{|l|}{ Ind-LSCS } & \multirow{4}{*}{0.018} \\
\hline NPOL & 40 & 17 & \\
\hline Failed induction & 33 & 11 & \\
\hline Fetal distress & 27 & 72 & \\
\hline $\begin{array}{l}\text { Maternal } \\
\text { complication }\end{array}$ & 33 & 67 & 0.385 \\
\hline \multicolumn{3}{|c|}{ Fetal complication } & \multirow{3}{*}{0.83} \\
\hline NICU & 38.5 & 61.5 & \\
\hline MSL & 33 & 67 & \\
\hline
\end{tabular}

A total $40 \%$ pregnant women of Group A had caesarean for NPOL and $33 \%$ for failed induction. The difference in indications for caesarean rate was statistically significant ( $p$ value $=0.018$ ). Maximum pregnant women had vaginal delivery in Group B i.e., $61.5 \%$ whereas majority of caesarean delivery was seen in Group A $62.5 \%$ (p value $=0.01)$. Maximum maternal complications $(67 \%)$ was seen in Group B. Majority of neonates with meconium stained liquor belonged to Group B (67\%) and $61.5 \%$ of neonates of Group B seeked NICU admission (Table 4).

\section{DISCUSSION}

Induction of labour is often a common practice among the obstetric practice. Conventionally cheap and feasible method used for pre-induction cervical ripening is intracervical Foley's catheter especially in a developing country like India. Misoprostol is a synthetic analogue of naturally occurring prostaglandin E1 which was originally manufactured for the treatment of peptic ulcer.

In the present study, there was no statistical difference between demographic variables like maternal age, socioeconomic status, parity, gestational age and BMI between the two groups. Most of this study recruited pregnant women were young primigravida suggesting the inclination towards their belief and willingness of hospital deliveries. This study is in contrast to a study by Agarwal et al, that observed $70 \%$ of the Foley's catheter and $50 \%$ of misoprostol group were primigravida. ${ }^{10}$ In a study by Noor et al 31.8\% women of Foley's catheter and $41.7 \%$ women of misoprostol group were primigravida. ${ }^{11}$

Most of the pregnant women in both the groups presented before their expected date at the time of recruitment. In a study by Promila et al, they observed that maximum pregnant women belonged to term gestation with mean gestational age of 38 weeks in Foley's catheter while 38.5 weeks in misoprostol group. ${ }^{12}$ Other studies by Roudsari et al, Sujata et al had similar results for mean gestational age of 38-39 weeks in both the groups. ${ }^{13,14}$ This study is in contrast to a study by Agarwal et al that observed 52\% of the misoprostol and $54 \%$ of the Foley's catheter group belonged to term gestation. ${ }^{10}$

The bishop score of $74 \%$ of the pregnant women in Foley's catheter and $86 \%$ in misoprostol group was between 4 to 6 i.e., majority of women had poor preinduction bishop score at the time of recruitment.

Majority of pregnant women in both Foley's catheter (48\%) and misoprostol (42\%) group were induced for borderline oligohydramnios. Second most common indication was post-dated pregnancy in both the groups. Fareed et al who found post-dated pregnancy as most common indication for induction of labour in both Foley's catheter and misoprostol group. ${ }^{15}$ Other studies by Sujata et al, Noor et al also concluded that post- dated pregnancy and oligohydramnios were main indication for induction of labour. ${ }^{11,14}$ This study is not concordant with study done by Promila et al and Agarwal et al that showed PIH as the main indication for induction in $42 \%$ in misoprostol and Foley's catheter group. ${ }^{10,12}$

The induction was successful in $80 \%$ pregnant women of the Foley's catheter and $96 \%$ of the misoprostol group 
which was statistically significant $(\mathrm{p}=0.013) . \quad 77.5 \%$ pregnant women in Foley's catheter and $70.8 \%$ in misoprostol group required augmentation with oxytocin. This study is concordant with an earlier study conducted by Promila et al that showed $98 \%$ of pregnant women had successful induction with misoprostol and $78 \%$ were successfully induced with Foley's catheter. ${ }^{12}$ This study is in contrast to an earlier study by Sheikher et al which compared between vaginal misoprostol and intracervical Foley's catheter and found that maximum number of pregnant women had successful induction when induced with Foley's catheter. ${ }^{16}$

The effect of parity on time lag between induction to delivery in successfully induced cases shows that Foley's catheter is better inducing technique in multigravida (15.44 hours) as compared to primigravida (20.11 hours). Misoprostol was found to be equally effective in all pregnant women irrespective of their parity with no statistical difference and without compromising the outcome. This study is in accordance with an earlier study conducted by Nazneen et al, Noor et al that showed induction-delivery interval was 9.2 hours in misoprostol as compared to 14.8 hours in Foley's catheter group. ${ }^{11,12,15,17}$ This study is in contrast to a study done by Sujata et al that showed the mean time from inductiondelivery interval was slightly more in misoprostol (21 hours 4 minutes) as compared to Foley's catheter group (19 hours 18 minutes) both in primigravida as well as multigravida. ${ }^{14}$

Considering the effect of period of gestation on time lag between induction to delivery in successfully induced cases, it was found that post-dated women took more time from induction till delivery (20.56 versus 14.46 hours) as compared to term gestation (16.52 versus 10.36 hours) in Foley's catheter and misoprostol group respectively. Noor et al did similar study in women with post-dated pregnancy which showed mean time of 18 hours 40 minutes for induction-delivery interval in Foley's catheter and mean time of 14 hours 03 minutes in misoprostol group. ${ }^{11}$ This study is contrast to a study by Sujata et al which reported that induction to delivery interval was 19.18 hours in Foley's catheter and 21.04 hours in misoprostol group. ${ }^{14}$

Failed induction was responsible for cesarean in $33 \%$ of Foley's catheter and $11 \%$ of misoprostol group of pregnant women. The incidence of cesarean in Foley's catheter group was observed high $(62.5 \%)$ because it also included cases with failed induction. Thus, authors didn't find any statistical difference in cesarean section rate between the two groups once authors excluded cases of failed induction which were significantly more in Foley's catheter group. Promila et al, concluded that fetal distress was main indication for the cesarean in both Foley's catheter and misoprostol group. ${ }^{12}$ Masood et al demonstrated that 33\% women in Foley's catheter and $28 \%$ women in misoprostol group had cesarean for failed induction. ${ }^{18}$ Agarwal et al also favors fetal distress as the main reason for cesarean in both misoprostol and Foley's catheter group. ${ }^{10}$ Results of this study was in accordance with above studies. This study is in consistent with other studies that also concluded the same inference that vaginal delivery was more common with misoprostol as compared to that of Foley's catheter. ${ }^{12,13,16}$ This study is in contrast to a study by Nazneen et al that showed $36 \%$ of the miosprostol and $10 \%$ of the Foley's catheter group had delivery by cesarean. ${ }^{17}$ Sujata et al observed the mode of delivery as vaginal in $80 \%$ of the Foley's catheter and $60 \%$ of the misoprostol group. ${ }^{14}$ This study is not in concordance with above two studies.

Foley's catheter group had less complications of tachysystole and hypertonus as compared to misoprostol ( $p$ value $=0.385$ ). In a study by Promila et al, tachysystole was noticed in $8.19 \%$, hypertonus in $3.3 \%$, hyperstimulation in $8.19 \%$ of the misoprostol and none of the Foley's catheter group. ${ }^{12}$ In a study by Roudsari et al, tachysystole was seen in $2 \%$, atony in $6 \%$ and uterine hypertonicity in $2 \%$ cases of misoprostol whereas $5 \%$ cases of Foley's catheter group had atony. ${ }^{13}$

The birth weight was more than $2.8 \mathrm{~kg}$ in $46 \%$ of the Foley's catheter and $48 \%$ in misoprostol group neonates. The incidents of meconium stained liquor were significantly more in misoprostol group and had NICU admission ( $p$ value $=0.83$ ). In a study by Promila et al, meconium stained liquor was present in two cases of misoprostol and one Foley's catheter group whereas three in misoprostol and one neonate in Foley's catheter group were admitted to NICU. ${ }^{12}$ Roudsari et al, concluded that ten percent of the misoprostol and five percent in the Foley's catheter group had meconium stained amniotic fluid. ${ }^{13}$ In a study by Noor et al, the NICU admission was observed in $13.3 \%$ of the misoprostol and $13.6 \%$ of the Foley's catheter group whereas meconium stained liquor was observed in $8.3 \%$ of the misoprostol and $9.1 \%$ of the Foley's catheter group. ${ }^{11}$ Results of this study was in consistent with above studies.

Limitations of the study was small sample size to compare, even though the study had sound methodology. This study requires future research in this direction to bring out more facts about the induction of labour.

\section{CONCLUSION}

This prospective comparative study was mainly undertaken to compare the efficacy and safety of misoprostol and Foley's catheter with oxytocin among the term pregnant women. The Misoprostol group was found to be better method of induction as compared to Foley's catheter group especially with respect to successful induction, requirement of augmentation and the reduction of induction to delivery interval. Foley's catheter was found to be better in respect to induction technique in multigravida and also having lesser maternal and fetal complications. Although Foley's catheter 
resulted in a greater number of failed induction but caesarean section rate was comparable in both the groups.

\section{ACKNOWLEDGMENTS}

Authors would like to thank all patients who helped by extreme co-operation to finish this study. Authors also thankful to clerks of record room to maintain the documents.

\section{Funding: No funding sources}

Conflict of interest: None declared

Ethical approval: The study was approved by the Institutional Ethics Committee

\section{REFERENCES}

1. Cunningham GF, Leveno KJ, Bloom SL, Hauth JC, Gilstrap L, Wenstorm KD. Normal labour and delivery. Chapter In: William's Obstetrics. $22^{\text {nd }}$ ed. McGraw Hill; 2005:409-442.

2. Dasgupta S. Induction of labour: Recent trends. Chapter In: Biswas A, eds. Recent Advances in Obstetrics and Gynaecology, volume 4. New Delhi: JP publications; 2013;4:13-28.

3. Cunningham GF, Leveno KJ, Bloom SL, Hauth JC, Gilstrap L, Wenstorm KD. Normal labour and delivery. Chapter In: William's Obstetrics. $22^{\text {nd }}$ ed. McGraw Hill; 2005:412-448.

4. Cheng YW, Shaffer BL, Caughey AB. The association between persistent occiput posterior position and neonatal outcomes. Obstet Gynecol. 2006;107(4):837-44.

5. Gupta N, Mishra SL, Jain S. A randomized clinical trial comparing Misoprostol and Dinoprostone for cervical ripening and labour induction. J Obstet Gynecol India. 2006;62(2):149-51.

6. Chandraharan E, Kumaran SA, editor the management of labour. $2^{\text {nd }}$ ed., Orient Longman Company; 2002:1-22.

7. Arulkumaran S, Gibb DM, TambyRaja RL, Heng SH, Ratnam SS. Failed induction of labour. Austr NZ J Obstet Gynecol. 1985;25:190-3.

8. Crane J, Johns NF. SOGC clinical practice guidelines, induction of labour at term. J Obstet Gynaecol Can. 2001;23(8):717-28.

9. Abbasi N, Danish N, Shakoor F, Parveen Z, Bilal SA. Effectiveness and safety of vaginal Misoprostol for induction of labour in unfavorable cervix in $3^{\text {rd }}$ trimester. J Ayub Med Coll Abbottabad. 2008;20(3):33-5.

10. Agarwal M, Kose V. Comparative study of vaginal misoprostol and intra cervical Foley's catheter for pre-induction cervical ripening at term. Int J Reprod Contracept Obstet Gynecol. 2017;6:1283-7.

11. Noor N, Ansari MS, Ali M. Comparison of vaginal Misoprostol and Foley catheter for cervical ripening. IJSR. 2015;1:475-8.

12. Promila J, Kaur GB, Bala T. A comparison of vaginal misoprostol versus Foley's catheter with oxytocin for induction of labor. J Obstet Gynecol India. 2007;57(1):42-7.

13. Roudsari FV, Ayati S, Ghasemi M, Mofrad MH, Shakeri MT, Farshidi F, et al. Comparison of vaginal misoprostol with Foleys catheter for cervical ripening and induction of labour. Iranian $\mathrm{J}$ Pharma Res. 2011;10(1):149-54.

14. Sujata, Iqbal B, Das V, Agarwal A, Singh R, Evaluation of non-pharmacological method transcervical foley catheter to intravaginal misoprostol and prostaglandin E2 gel for preinduction cervical ripening. Biomed Res. 2012;23(2):247-51.

15. Fareed $\mathrm{P}$, Malik $\mathrm{S}$, Nazir $\mathrm{T}$, Kawoosa $\mathrm{S}$. Comparative study of intra-cervical Foley's catheter and vaginal misoprostol for pre-induction cervical ripening. Int J Sci Stud. 2015 3(4):40-3.

16. Sheikher C, Suri N, Kholi U. Comparative evaluation of oral misoprostol, vaginal misoprostol and intracervical Foley's catheter for induction of labour at term. JK Sci. 2009;11(2):75-7.

17. Nazeen S, Sultana F, Nahaer K. Intravaginal misoprostol versus transcervical Foley catheter for pre- induction cervical ripening and their outcome: a comparative study. Bangladesh J Obstet Gynaecol. 2012;27(2):72-8.

18. Masood A. Intracervical foley catheter versus vaginal prostaglandins for induction of labor in women with previous one cesarean section-a pilot study. Obstet Gynecol Int J. 2015;2(5):160-4.

Cite this article as: Priyanka, Arya SB, Sinha M, Goel JK. A comparative study of intracervical foley's catheter with oxytocin and vaginal misoprostol for induction of labour. Int J Reprod Contracept Obstet Gynecol 2020;9:3660-4. 